\title{
Lack of evidence for mutation to erythromycin resistance in clinical strains of Staphylococcus aureus
}

\author{
R. W. LACEY
}

From the Department of Pathology, West Norfolk and King's Lynn General Hospital

SUMMARY The properties of 100 erythromycin resistant strains of Staphylococcus aureus obtained from clinical material have been compared with the properties of mutants selected in vitro for resistance to erythromycin. The properties, including inducibility of the resistance and cross-resistance to spiramycin and lincomycin, of the two groups of isolates were always different. The risk that staphylococci will mutate to erythromycin resistance during therapy with this antibiotic is remote.

Soon after erythromycin was introduced, strains of Staphylococcus aureus and other species appeared that were resistant to this antibiotic. Erythromycin resistant organisms were also relatively easy to select from sensitive bacterial populations in vitro. These observations resulted in the recommendation that there should be some restriction in the use of erythromycin in order to limit the incidence of resistant bacteria. Also, erythromycin was often used either in short courses or combined with another antibiotic in order to reduce the apparent risk of mutation to resistance (Cruickshank et al., 1973).

However, two aspects of erythromycin resistance in Staph. aureus posed problems:

1 The mutants selected in vitro were often slow growing and unstable, whereas resistant isolates from clinical material generally had normal growth rates and appeared to be fully virulent (Garrod et al., 1973).

2 The nature of the resistant clinical isolates sometimes differed from the laboratory mutants in that the former could be resistant to erythromycin only (dissociated resistance; see Garrod (1957) and Weaver and Pattee (1964)) whereas the latter were always resistant to other macrolide antibiotics in addition to erythromycin.

These phenomena suggest that the laboratory manipulations may not always be a true reflection of the occurrence of events in vivo; ie, the explanation for erythromycin resistant bacteria appearing in vivo may not be a succession of mutants as presumably occurs with 'training' methods in vitro.

In this paper the properties of 100 naturally

Received for publication 19 January 1977 occurring erythromycin resistant strains of Staph. aureus are compared with those of isolates made resistant in vitro. In no instance has a clinical isolate been found to possess properties identical with those of laboratory mutants.

\section{Material and methods}

STRAINS OF STAPHYLOCOCCUS AUREUS

Twenty recent clinical isolates of different phage typing pattern were used in an attempt to select erythromycin resistant mutants in vitro. One hundred erythromycin resistant strains of Staph. aureus were collected from clinical material in Bristol (52) between 1969 and 1974 and in King's Lynn and Wisbech (48) between 1974 and 1976. Each isolate was judged to be epidemiologically distinct, and the majority (72) had different sensitivity to antibiotics other than erythromycin or different phage typing patterns. The isolates were stored on nutrient agar slopes at room temperature without subculture. Before detailed examination, single colony isolates were obtained and stored on nutrient agar plates at $4^{\circ} \mathrm{C}$.

DETERMINATION OF SENSITIVITY Minimum inhibitory concentrations (MIC) of antibiotics were detected as previously, using an agar $\varrho$

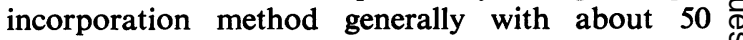
colony-forming units per inoculum (Lacey et al., 1975).

MEDIA

Nutrient agar used throughout was Oxoid Blood Base No. 2. Peptone water was Oxoid (CM9).

Phage typing was performed as previously (Lacey 
et al., 1975) with the inclusion of the new phages 94 and 96.

\section{ANTIBIOTICS}

Erythromycin ethyl succinate (Abbott), Spiramycin (May and Baker), and Lincomycin hydrochloride (Upjohn) were used in concentrations equivalent to each base. Erythromycin ethyl succinate was dissolved in ethylene glycol before addition to media.

\section{Results}

\section{DEVELOPMENT OF ERYTHROMYCIN}

RESISTANCE IN VITRO

Nutrient agar plates (containing no antibiotics) were inoculated in duplicate from single colonies of each of 20 erythromycin sensitive (MIC $=0.25 \mu \mathrm{g}$ erythromycin per $\mathrm{ml}$ ) strains. Plates were then incubated for $18 \mathrm{~h}$ at $37^{\circ} \mathrm{C}$ and the surface cultures that resulted were combined for each strain into 10 $\mathrm{ml}$ quarter strength Ringer solution. Surface viable counts were performed on $0.1 \mathrm{ml}$ of each of the resultant slurries, and then $1 \mathrm{ml}$ of each of the slurries was applied in duplicate to the surface of the nutrient agar plates containing $0 \cdot 1,1,5$ or $50 \mu \mathrm{g}$ erythromycin $/ \mathrm{ml}$. After drying the plates were incubated for $48 \mathrm{~h}$ at $37^{\circ} \mathrm{C}$. As expected, the surface of all plates containing $0 \cdot 1 \mu \mathrm{g}$ erythromycin $/ \mathrm{ml}$ contained confluent growth. All 20 strains yielded small discrete colonies on agar containing $1 \mu \mathrm{g} / \mathrm{ml}$, but only seven strains produced any colonies on media containing $5 \mu$ g erythromycin $/ \mathrm{ml}$, and no bona fide mutants were detected on nutrient agar containing $50 \mu \mathrm{g}$ erythromycin/ml. (During the course of these experiments a few highly resistant colonies were detected, but investigation of these, including phage typing pattern, indicated that none was Staph. aureus.)

The number of bacteria inoculated onto each plate varied from $8 \times 10^{11}$ to $2.0 \times 10^{13}$, so that from a total of about $5 \times 10^{14}$ bacteria applied not a single high-level (resistant to $50 \mu \mathrm{g}$ erythromycin $/ \mathrm{ml}$ ) one-step mutant was obtained. However, since erythromycin resistance in clinical strains is usually inducible (see below), the failure to detect such mutants could be because the cultures had not been exposed previously to subinhibitory concentrations of erythromycin. To exclude this possibility, the slurry from agar containing $0 \cdot 1 \mu \mathrm{g}$ erythromycin $/ \mathrm{ml}$ was applied to the surface of nutrient agar plates containing $50 \mu \mathrm{g} / \mathrm{ml}$ of the drug. After $48 \mathrm{~h}$ incubation at $37^{\circ} \mathrm{C}$ no colony appeared from an inoculum of $3 \times 10^{14}$ bacteria.

However, when the cultures were transferred as above from media containing $0 \cdot 1 \mu \mathrm{g}$ erythromycin/ $\mathrm{ml}$ successively to $1,5,25$, and then $50 \mu \mathrm{g} / \mathrm{ml}$ con- centrations, each plate yielded either semiconfluent growth or discrete colonies. However, every resistant colony so produced was much smaller than equivalent colonies on similar media from naturally occurring resistant isolates, or from sensitive staphylococci inoculated onto antibiotic free media. Two colonies of each strain were picked from the agar containing $50 \mu \mathrm{g}$ erythromycin/ml and examined further.

\section{PROPERTIES OF ERYTHROMYCIN RESISTANT}

MUTANTS SELECTED IN VITRO

The 40 mutants were picked off onto nutrient agar, phage typed, and then inoculated into peptone water for MIC determination. All were inhibited by between 5 and $100 \mu \mathrm{g}$ erythromycin $/ \mathrm{ml}$ and between 25 and $1000 \mu \mathrm{g}$ spiramycin $/ \mathrm{ml}$. All were more resistant, by a factor of at least fivefold, to spiramycin than to erythromycin (Table 1).

That some were inhibited by levels as low as $5 \mu \mathrm{g}$ erythromycin $/ \mathrm{ml}$ was due to instability of the resistance. Sixteen of the $\mathbf{4 0}$ isolates showed this after three subcultures, when the population of bacteria comprised a mixture of slow-growing erythromycin resistant colonies (colony diameters $\sim 0.5 \mathrm{~mm}$ ) and normal growing colonies (colony diameter $>2 \mathrm{~mm}$ ) that were either sensitive (MIC $<0.5 \mu \mathrm{g} / \mathrm{ml}$ ) or only slightly resistant (MIC 0.5-5 $\mu \mathrm{g} / \mathrm{ml}$ ).

None of the mutants was resistant to high levels of lincomycin ( $\mathrm{MIC}<1.0 \mu \mathrm{g} / \mathrm{ml})$.

It has been found that pre-incubation of resistant colonies from clinical material in peptone water containing $0.10 \mu \mathrm{g} / \mathrm{ml}$ erythromycin is adequate to cause full induction of erythromycin resistance (Weaver and Pattee, 1964). The mutants were therefore incubated in peptone water containing either $0.02 \mu \mathrm{g}$ or $0.20 \mu \mathrm{g}$ erythromycin $/ \mathrm{ml}$ before determination of MICs. This treatment did not increase the level of resistance to either erythromycin, lincomycin or spiramycin, ie, the resistance of the mutants was non-inducible.

PROPERTIES OF ERYTHROMYCIN

RESISTANT STRAINS OF

STAPHYLOCOCCUS AUREUS ISOLATED FROM

CLINICAL MATERIAL

All the isolates produced normal colonies morphologically and were coagulase and DNAse positive. Sixty-one were obtained from lesions with pus. Single cell MICs were obtained after incubation in peptone water with or without the addition of 0.02 $\mu$ g erythromycin $/ \mathrm{ml}$.

Three patterns of sensitivity resulted (Table 2):

1 Inducible resistance to erythromycin in 84 strains In these, the MIC of erythromycin without pre- 
Table 1 Properties of erythromycin resistant mutants of Staph. aureus selected in vitro compared to resistant clinical strains

\begin{tabular}{llll}
\hline & Colonial appearance & Stability of resistance & Inducibility \\
\hline Mutants selected in vitro & $\begin{array}{l}\text { Small size } \\
(\sim 0.5 \mathrm{~mm} \text { diam) }\end{array}$ & Usually unstable & Never inducible \\
Clinical resistant isolates & $\begin{array}{l}\text { Normal } \\
(>2 \mathrm{~mm} \text { diam) }\end{array}$ & Stable & $\begin{array}{l}\text { Always resistant to } \\
\text { spiramycin and sensitive to } \\
\text { lincomycin } \\
\text { Varies (see text) but never } \\
\text { as for mutants selected } \\
\text { in vitro }\end{array}$ \\
\end{tabular}

Table 2 Properties of erythromycin resistant isolates of Staph. aureus isolated obtained from clinical material

\begin{tabular}{|c|c|c|c|c|c|c|c|c|}
\hline \multirow[t]{2}{*}{ Resistance pattern } & \multirow[t]{2}{*}{ Total number } & \multicolumn{4}{|c|}{ Phage groups } & \multicolumn{3}{|c|}{ Antibiogram } \\
\hline & & $I$ & II & $I I I$ & $N T$ & $P$ & $T$ & $N$ \\
\hline \multirow{3}{*}{$\begin{array}{l}\text { Inducible resistance to erythromycin, } \\
\text { sensitive to spiramycin and lincomycin } \\
\text { Constitutive resistance to erythromycin and } \\
\text { spiramycin; sensitive to lincomycin } \\
\text { Constitutive resistance to erythromycin, } \\
\text { spiramycin and lincomycin }\end{array}$} & 84 & 4 & 1 & 63 & 16 & 60 & 41 & 11 \\
\hline & 10 & $\mathbf{0}$ & $\mathbf{0}$ & 8 & 2 & 10 & 9 & 3 \\
\hline & 6 & 0 & 0 & 6 & 0 & 6 & 5 & 0 \\
\hline
\end{tabular}

NT = non-typable (routine test dilution)

PTN = resistance to penicillin, tetracycline, neomycin.

incubation with the antibiotic varied from 1 to 25 $\mu \mathrm{g} / \mathrm{ml}$. After pre-incubation, the MIC was always greater than $1000 \mu \mathrm{g} / \mathrm{ml}$. These strains were sensitive to lincomycin (MIC $<1 \mu \mathrm{g} / \mathrm{ml})$ and spiramycin (MIC $<25 \mu \mathrm{g} / \mathrm{ml}$ ) whether or not the cultures were pre-incubated with erythromycin. On disk testing with lincomycin and erythromycin disks adjacent, all these strains showed 'dissociated' resistance in which the presence of erythromycin appeared to cause resistance to lincomyin (Garrod et al., 1973). However, by MIC determination erythromycin did not seem to induce lincomycin resistance (see above), so the explanation for this type of zone phenomenon on disk testing is unexplained. However, in other properties these isolates resembled those erythromycin resistant isolates described by Garrod (1957) as possessing dissociated resistance.

2 Constitutive resistance to erythromycin in 10 strains

In these, every cell of a culture was highly resistant to erythromycin (MIC $>1000 \mu \mathrm{g} / \mathrm{ml}$ ) whether or not it had been pre-incubated with erythromycin. These strains were sensitive to lincomycin and spiramycin even after pre-incubation with erythromycin.

3 Constitutive resistance to erythromycin, lincomycin, and spiramycin in 6 strains

In these, every cell was resistant (MIC $>1000 \mu \mathrm{g} / \mathrm{ml}$ ) to each of these antibiotics whether or not the cultures had been pre-incubated with subinhibitory concentrations of erythromycin.

\section{Discussion}

The difficulty with which erythromycin resistant mutants can be selected in vitro was notable. From more than a total of $10^{14}$ cells of 20 strains of sensitive staphylococci not a single one-step highlevel (MIC $>50 \mu \mathrm{g} / \mathrm{ml})$ mutant could be obtained. This contrasts markedly with the ease with which one-step mutants resistant to novabiocin, streptomycin, or rifampicin can be selected in vitro (Lacey, 1972). However, by serial transfer of cultures in media containing increasing levels of antibiotic, colonies resistant to erythromycin could be isolated. The properties of these mutants were similar, namely, the resistant colonies were small and the resistance was unstable. Also, on first isolation the mutants showed resistance to both erythromycin and spiramycin. The level of resistance to spiramycin was always greater than that to erythromycin.

In contrast, none of the resistant isolates from clinical material showed any of these features. The majority possessed an inducible resistance to erythromycin and sensitivity to spiramycin and lincomycin. The minority showed either a high level constitutive resistance (MIC $>1000 \mu \mathrm{g} / \mathrm{ml}$ ) to all three antibiotics or to erythromycin alone.

The two types of resistance shown by clinical and laboratory strains are therefore well defined and distinct. It is not possible to account for the appearance of these resistant clinical isolates on the basis of 
laboratory manipulation as above. The origin of erythromycin resistance in clinical strains is obscure, but the following considerations are consistent with the proposal that a very few sets of genes are responsible for this resistance.

1 With one exception, the resistance in the strains in this survey was confined to staphylococci of phage groups I and III or strains that were non-typable. Such strains have probably evolved rapidly in nature with loss and gain of prophages and antibiotic resistance genes (Jevons et al., 1966; Lacey, 1975). Thus the presence of erythronycin resistant strains of diverse properties need not be due to the evolution of the resistance de novo in each isolate. Rather it could indicate that few erythromycin resistant strains have evolved over the years to produce a variety of resistant isolates due to the natural variation of these other unstable properties.

2 Erythromycin resistance has been shown to be plasmid mediated and can be transferred between strains of Staph. aureus by transduction (Lacey, 1975).

3 Becuase erythromycin resistance is inducible, a complex mechanism must exist to effect this. It is reasonable to conclude that this has evolved infrequently on the grounds of improbability. It is not surprising that none of the laboratory mutants showed inducibility.

The relevance of these findings for the clinical use of erythromycin may be considerable. If these findings are extended to the clinical situation the risk that a population of staphylococci initially uniformly sensitive will mutate to erythromycin resistance during therapy, however prolonged, appear to be slight. Any mutants that might appear will be expected to be slow-growing and probably nonpathogenic. Thus, in domiciliary patients, there seems to be no reason to withhold deliberately the use of erythromycin for fear of selecting resistance. This argument probably also applies to the use of this antibiotic against other bacteria, eg, Streptococcus pyogenes, Streptococcus pneumoniae, and Haemophilus influenzae that have been less prone to acquire resistance than Staph. aureus. Indeed, it has been impossible to select in one step mutants of any of these bacteria highly resistant to erythromycin (MIC $>100 \mu \mathrm{g} / \mathrm{ml}$ ).

In hospital environments where erythromycin resistant staphylococci exist there is a risk that the lavish use of erythromycin will select these isolates. However, this argument applies also to the use of other antibiotics, so that the use of erythromycin with care should not be expected to be specifically liable to select resistant bacteria.

\section{References}

Cruickshank, R., Duguid, J. P., Marmion, B. P., and Swain, R. H. A. (1973). Medical Microbiology, 12th ed., Vol. I. Churchill Livingstone, Edinburgh and London.

Garrod, L. P. (1957). The erythromycin group of antibiotics. British Medical Journal, 2, 57-63.

Garrod, L. P., Lambert, H. P., and O'Grady, F. (1973). Antibiotic and Chemotherapy. 4th ed. Churchill Livingstone, Edinburgh and London.

Jevons, M. P., John, M., and Parker, M. T. (1966). Cultural characters of a newly recognised group of hospital staphylococci. Journal of Clinical Pathology, 19, 305-312.

Lacey, R. W. (1972). Transfer of chromosomal genes between staphylococci in mixed cultures. Journal of General Microbiology, 71, 399-401.

Lacey, R. W. (1975). Antiobiotic resistance plasmids of Staphylococcus aureus and their clinical importance. Bacteriological Reviews, 39, 1-32.

Lacey, R. W., Lewis, E., and Harrison, J. (1975). Variation in the properties of a strain of Staphylococcus aureus isolated over three months from a single hospital. Journal of Medical Microbiology, 8, 39-46.

Weaver, J. R. and Pattee, P. A. (1964). Inducible resistance to erythromycin in Staphylococcus aureus. Journal of Bacteriology, 88, 574-580. 